\title{
Diffusion-weighted MRI for detecting and monitoring cancer: a review of current applications in body imaging
}

\author{
Barış Türkbey, Ömer Aras, Nevzat Karabulut, Ahmet Tuncay Turgut, Erhan Akpınar, Sedat Alibek, \\ Yuxi Pang, Şükrü Mehmet Ertürk, Riham H. El Khouli, David A. Bluemke, Peter L. Choyke
}

\begin{abstract}
Diffusion-weighted magnetic resonance imaging (MRI), which involves the acquisition of a magnetic resonance signal related to the Brownian motion of water protons in tissue, has become a useful technique for assessing tumors. In this article, we review the basic concepts, imaging strategies, and body applications of diffusion-weighted MRI in detecting and monitoring cancer.
\end{abstract}

Key words: • cancer $\bullet$ diffusion weighted magnetic resonance imaging $\bullet$ body applications
From the Molecular Imaging Program (B.T. $\square$ bturkbey@yahoo. com, Ö.A., P.L.C.), National Cancer Institute, NIH, Bethesda, MD, USA; the Department of Radiology (N.K.), Pamukkale University School of Medicine, Denizli, Turkey; the Department of Radiology (A.T.T.), Ankara Training and Education Hospital, Ankara, Turkey; the Department of Radiology (E.A.), Hacettepe University Faculty of Medicine, Ankara, Turkey; the Radiology Institute (S.A.), University of Erlangen, Erlangen, Germany; Philips Healthcare (Y.P.), Cleveland, OH, USA; the Department of Radiology (Ş.M.E.), İstanbul Şişli Etfal Training and Research Hospital, Istanbul, Turkey; Radiology and Imaging Sciences (D.A.B.), National Institutes of Health/Clinical Center and the National Institute of Biomedical Imaging and Bioengineering, Bethesda, MD, USA.

Received 2 June 2011; revision requested 9 June 2011; revision received 14 June 2011; accepted 14 June 2011.

Published online 16 September 2011

DOI 10.4261/1305-3825.DIR.4708-11.2 maging is used to detect, characterize, and monitor cancer. Recently, diffusion-weighted magnetic resonance imaging (DWI) has become a useful adjunct for assessing tumors with magnetic resonance imaging (MRI). DWI involves the acquisition of a magnetic resonance signal related to random thermal motion (Brownian motion) or the "diffusion" of water protons in tissue. The signal obtained with DWI is a measure of the net displacement of water molecules, e.g., the water path length in the extracellular, intracellular and intravascular spaces. This motion is largely random and can be reduced by structural barriers, such as cell membranes and collagen. Restricted diffusion in biological tissues is inversely proportional to tissue cellularity and the integrity of cell membranes, and it can be quantified with apparent diffusion coefficient (ADC) measurements (1). Depending on the microarchitecture, either restricted or increased diffusion can occur in malignant tumors. For instance, diffusion is restricted in cellular portions of the tumor, but it may be increased in necrotic portions $(2,3)$. Other causes of enhanced diffusion include increased water content arising from intratumoral edema and cystic tumor components (4-6).

Although initially used to evaluate neurological diseases, the applications of DWI have been extended to oncologic imaging throughout the body made possible by improvements in MRI hardware and new sequences. The use of DWI as a complement to conventional MRI methods has led to improvements in the detection and characterization of tumors, treatment response monitoring, and detection of recurrence in oncology patients.

\section{Basic concepts of DWI}

In 1965, Stejskal and Tanner (7) proposed the application of a symmetric pair of additional gradients on either side of the $180^{\circ}$ refocusing radiofrequency pulse. The Stejskal-Tanner sequence is still the basis of modern DWI. For static water molecules, the phasing effect caused by the first gradient will be reversed by the second gradient, leading to no signal loss; however, this phasing effect will not be completely reversed if the water molecules are not stationary, which results in the observed well-known diffusion signal decay. The amount of diffusion weighting is determined by the $b$ value, which describes the amplitude, duration of the applied gradient, and time interval between the two diffusion gradients (4). The degree of signal attenuation from water molecules is correlated with the $b$ value. Low $b$ values indicate flow or perfusion movement, whereas high $b$ values (e.g., $\mathrm{b}=1.000 \mathrm{~s} / \mathrm{mm}^{2}$ ) indicate slow-moving water molecules (1). A minimum of two $b$ values are necessary for DWI and the calculation of ADC. The evaluation of the data provided by DWI can be either qualitative or quantitative. Qualitative evaluation involves visually assessing the relative signal intensity attenuation of images 
obtained at different $b$ values and enables tissue characterization based on differences in water diffusion $(1,4)$. From a clinical point of view, qualitative assessment can help to detect and characterize tumors, monitor the treatment response, and detect recurrence in patients with cancer. Trace or index diffusion-weighted images are the sum of images acquired by applying diffusion gradients in each of the three orthogonal directions. The signal intensity in these images is affected by both water diffusion and $\mathrm{T} 2$ relaxation time; thus, a tissue area with a very long $\mathrm{T} 2$ relaxation time may reveal a high signal that may be misinterpreted to represent restricted diffusion at DWI, a phenomenon that is also known as "T2 shine-through" (4). An additional entity is the "T2 dark-through" effect, which indicates hypointensity in both DWI and T2W MRI. Such effects, mainly secondary to susceptibility effects, are commonly seen in hematomas. The use of appropriate TE and $b$ values may reduce these effects.

In biological tissues, a quantitative analysis of DWI can be performed by calculating an ADC based on the relative signal intensity change of the tissue with increasing $b$ values (4). ADC maps are based on the slope of the line depicting signal loss with rising $b$ values. Values can be calculated on a voxel-by-voxel basis to provide ADC maps. Notably, restricted diffusion in highly cellular areas results in low ADC values compared with less cellular areas, which show higher ADC values.

\section{Imaging strategies}

Virtually any type of pulse sequence can be adapted for body DWI. These include spin-echo, stimulated-echo, echo-planar (EPI), turbo-spin-echo (TSE), and steady-state free-precession sequences. In general, the most popular pulse sequence for DWI is the single-shot spin-echo EPI sequence, which is less prone to motion artifacts. However, this technique has the inherent disadvantage of image distortion because of susceptibility artifacts and low spatial resolution, both of which limit its use in areas other than the brain (8). Recently, improvements in gradient systems and the application of parallel imaging techniques have improved the suitability of EPI for body DWI. Diffusion-weighted singleshot fast-spin-echo (or TSE) sequences, also known as diffusion-weighted "rapid acquisition with relaxation enhancement" (9) and "half-Fourieracquisition single-shot turbo-spinecho" (HASTE) sequences, and the recently proposed diffusion-weighted periodically rotated overlapping parallel lines with enhanced reconstruction (PROPELLER) sequence can also be used for DWI. These sequences are very fast and less prone to motion artifacts, although their spatial resolution is limited (8).

In DWI, the two greatest sources of image degradation are magnetic field inhomogeneity and motion artifacts. The main strategies used to improve image quality are breath-hold singleshot DWI and non-breath-hold multiple-averages DWI. DWI can also be performed at one location or at multiple stations, in which case the images can be "stitched" together to create a whole-body image (also known as diffusion-weighted whole-body imaging with background body signal suppression [DWIBS]) (4). The breath-hold DWI technique involves the quick acquisition of an image within a limited number of breath-holds. The speed is increased by using very short singleshot EPI echo times with parallel imaging and fat suppression $(4,10,11)$. Moreover, respiratory motion and volume averaging artifacts can be reduced. However, single-shot breath-hold EPI also has some inherent limitations, such as the limited number of $b$ values that can be acquired within the duration of a single breath-hold, reduced signal-to-noise ratio, and greater sensitivity to pulsatile and susceptibility artifacts (4). Non-breath-hold sequences, such as the non-breath-hold spin-echo EPI combined with fat suppression, can also be used for body DWI studies (4). The advantage of these sequences is the higher spatial resolution they provide. The technique improves the signal-to-noise and contrast-to-noise ratios by means of multiple-slice excitation and signal averaging over a longer duration (12). However, it is associated with a longer scanning time (3 to $6 \mathrm{~min}$ ), which enables the use of multiple (>5) $b$ values $(2,4)$. DWIBS is performed using a short tau inversion recovery (STIR) EPI technique with a high $b$ value $\left(1000 \mathrm{~s} / \mathrm{mm}^{2}\right)$ for background suppression. Free-breathing, multiple-averaging DWI is performed at contiguous stations in the body, and a composite image of the whole-body maximum intensity projection is displayed with an inverted gray scale on a white background (12). Although the signals from normal tissue (e.g., blood vessels, fat, muscle, and bowel) are suppressed, other normal structures (e.g., the spleen, prostate, testes, and ovaries) remain visible (12). The technique depicts tumors and some benign processes, such as abscesses, with areas of restricted diffusion (4). Additionally, the technique has been reported to be capable of depicting small foci of tumors within the abdomen or peritoneum (12). Similar to the non-breathhold technique, multiple-averaging DWI, e.g., DWIBS, offers the advantages of thin image partitions and a good signal-to-noise ratio. Nevertheless, the relatively long image acquisition time required to evaluate the whole body is a disadvantage.

In living organs, there are many ways to keep water molecules moving. Two of these are of particular relevance to DWI: the well-recognized thermally driven diffusion and the less-valued blood flow in the microvasculature (pseudodiffusion). The diffusion of water molecules is more restricted within a cell than outside because of the existence of cell membranes. Because the ADC reflects the diffusion from both intracellular and extracellular environments, this measure would be largely decreased if the extracellular space was to some extent compressed, leading to more weight on the intracellular portion of the ADC. As tumors aggressively grow, the number of tumor cells greatly increases (causing higher cellularity). These less-organized cells are closely compressed, leading to reduced extracellular space, which in turn results in a lower ADC. This phenomenon forms the basis for using ADC as a surrogate biomarker for tumor detection. In the 1980s, Le Bihan et al. (13) proposed a seminal theoretical model known as intravoxel incoherent motion (IVIM) MRI, which aimed to separate the active blood microcirculation (perfusion) from molecular diffusion in DWI. The water molecules in a capillary network mimic those engaging in Brownian motion because of the randomly organized capillary environments; however, each group of molecules exhibits distinct time and spatial scales to produce a pseudodiffusion coefficient one or two magnitudes larger than 
coefficient of its counterpart. Initially, IVIM was applied to neuroimaging. In recent years, however, IVIM has attracted renewed attention for body/ oncology applications because of higher available magnetic fields and better gradient hardware performance, which facilitates faster data acquisition and generates images of superior quality. Most importantly, IVIM has the potential to provide information about both the cellularity and perfusion of tumors; aggressive tumor growth is intrinsically associated with a higher number of tumor cells and greater angiogenesis. With the increasing awareness of the toxicity of MR contrast agents, IVIM could be considered a favorable alternative for deriving perfusion information without contrast agent injection (13-17).

\section{Optimization of the technique}

The optimization of the scanning parameters helps to improve the signaland contrast-to-noise ratio between the tumor and surrounding tissue. Fat suppression with an inversion recovery (e.g., STIR) technique is preferred for DWI when the field of view is large, whereas chemical-fat-selective saturation (e.g., spectral-selected attenuation with inversion recovery [SPAIR] or chemical-shift-selective [CHESS] imaging) or water-selective excitation may be used for selected body regions (4). In general, the acquisition time should be as short as possible. Moreover, the repetition time should be long enough to minimize T1 saturation effects, which would otherwise generate falsely low ADC values. The adapted $b$ values for body imaging should typically be lower than those for brain DWI, thus enabling an optimal image quality and reliable quantification (8).

\section{Current clinical applications \\ Pediatric applications}

With the rising concern about the effects of ionizing radiation from computed tomography (CT) imaging, DWI has been increasingly applied to pediatric populations. Experience is still limited, and most reports describe only initial experiences when using DWI as a part of pediatric MRI. In a small series, seven children with neuroblastomas demonstrated significantly higher contrast with DWI than with T2W MRI. The ADC was correlated with the tumor cellularity as revealed in the histology examination. It was suggested that DWI was helpful in the differential diagnosis of neuroblastoma and outlined the tumor better than other MRI techniques (18). This observation was validated in a study of 19 pediatric patients presenting with a variety of tumors; in that study, ADC values were not helpful in distinguishing malignant from benign lesions (19). Alibek et al. (20) reported the largest pediatric experience to date $(n=29)$ and showed that DWI correlated well with post-Gd T1W MRI in a variety of tumors, which therefore suggested that DWI might be a useful substitute in patients with advanced renal insufficiency. In a study of DWI in osteosarcoma, a significant increase in the ADC value was correlated with the tumor necrosis grade after chemotherapy, suggesting that ADC measurements might be a quantitative tool for assessing the response (Fig. 1) (21). Whole-body DWI is compelling because it can cover large regions of the body without requiring ionizing radiation (22). Thus, as a safe, radiation-free and noninvasive tool, DWI holds promise for a broad range of pediatric malignancies.

\section{Thoracic applications}

MRI of the lung using fast acquisition sequences with a high temporal resolution has become feasible with the recent developments in gradient technology, multichannel coils, and parallel imaging techniques (23). Experience with thoracic applications of DWI techniques is still growing, and preliminary studies have reported promising results (24-35).

In the chest, DWI is typically acquired in a transverse plane, using at least two $b$ values. Most studies employ the combination of low (0-50 s/ $\mathrm{mm}^{2}$ ) and intermediate-to-high $b$ values (400-1000 $\left.\mathrm{s} / \mathrm{mm}^{2}\right)$. Higher $b$ values generate more diffusion weighting at the expense of a reduced signal. Usually, diffusion gradients are applied in three directions to improve scanning efficiency. The STIR approach has been most commonly used for fat suppression to achieve a more accurate ADC estimation. Early studies employed free breathing or breath holding (24-35). The latter type of study can be completed in two or more separate breathholding scans. Respiratory or ECG gating has been used, but typically only at the lesion site rather than for the entire chest (25-27). The typical slice thickness is 4-9 $\mathrm{mm}$ with an interslice gap of $0-1.5 \mathrm{~mm}$, and the number of excitations ranges from 1 to 10 . Phasedarray surface coils are preferred because they improve the signal-to-noise ratio and allow parallel imaging, which reduces the acquisition time.

Chest DWIs can be evaluated qualitatively, semiquantitatively, and quantitatively. In qualitative evaluations, the chest wall muscles or spinal cord can be used as a standard of reference when evaluating the signal intensity of a target lesion $(24,27,28,36)$. Malignant lesions tend to be hyperintense relative to the chest wall muscles or spinal cord. Semiquantitative evaluation is performed by measuring the signal intensities of the lesion and comparing them with the spinal cord or chest wall muscles. The calculated ratio of the signal intensity of the lesion to that of the spinal cord has been used to differentiate between benign and malignant tumors (29). Quantitative DWI analysis relies on ADC measurement. A circular or elliptical region of interest (ROI) is drawn on the section where the target lesion was detected on the T2W or contrast-enhanced images. In heterogeneous tumors, care should be taken to place the ROI in the solid portion of the mass, excluding cystic or necrotic areas. DWI has been used to characterize lung lesions (27), to detect and classify adenocarcinomas (37), to predict tumor invasiveness in early-stage lung cancer (24), to detect tumors in collapsed lungs $(32,33)$, and for nodal staging of lung cancer $(26,35)$.

Most malignant lesions tend to be hyperintense relative to the chest wall muscles or the spinal cord on DWI images and hypointense on ADC maps (Fig. 2). In a series of 51 patients with 54 nodules, Satoh et al. (36) compared the signal intensity of nodules with that of the spinal cord and found that malignant nodules were significantly more hyperintense than benign nodules. The authors reported $89 \%$ sensitivity, $61 \%$ specificity, and $89 \%$ accuracy when the signal intensity of nodules was equal to or greater than that of the spinal cord. In contrast, Liu et al. (28) did not find significant signal intensity differences between benign and malignant nodules in an analysis of 66 pulmonary lesions. However, they reported 83\% sensitivity and $74 \%$ specificity using a threshold ADC value of $1.4 \times 10^{-3} \mathrm{~mm}^{2} / \mathrm{s}$. Kanauchi 

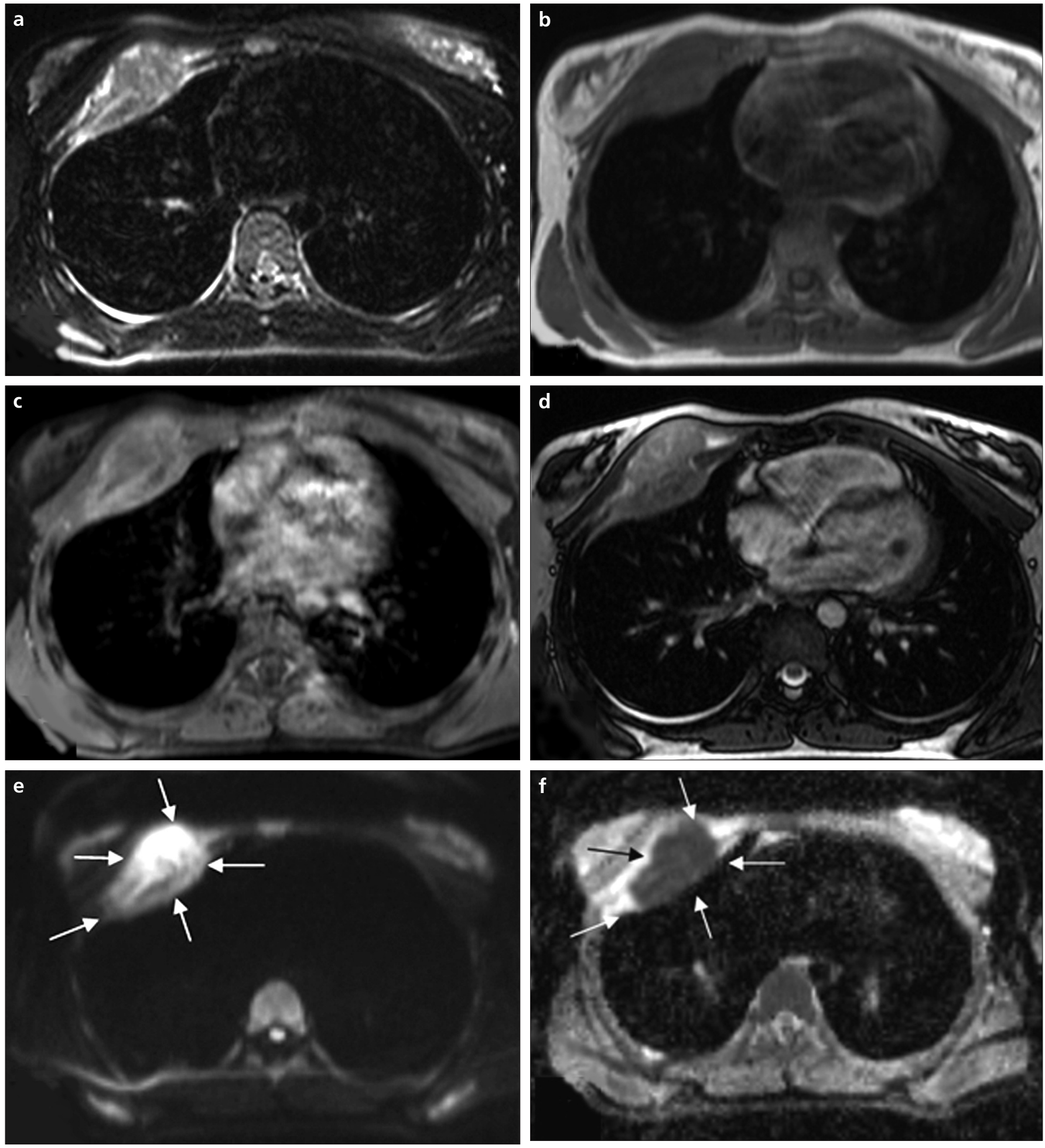

Figure 1. a-f. Axial T2W STIR (a), T1W TSE (b), T1W VIBE Gd enhanced (c), TRUFI (d), DWI (b=1000 s/mm²) (e), and ADC map (f) show tumor margins in an 11-year-old patient with osteosarcoma of the rib (arrows). The highest lesion in relation to the background contrast is appreciated on the DWI image and the ADC map (e and f).

et al. (24) investigated tumor invasiveness with qualitative DWI in 41 patients with stage IA non-small cell lung carcinoma using lesion-to-spinal-cord ratios (LSR). It was reported that DWI was an independent predictive factor for tumor aggressiveness. In a series of 28 patients, Uto et al. (29) compared the performance of LSR signal intensity with that of ADC and found that LSR was more accurate in distinguishing malignant from benign nodules. Using an LSR threshold of 1.135, they reported $83 \%$ sensitivity, $90 \%$ specificity, and $86 \%$ accuracy. ADC values have also had favorable results, with a sensitivity of $33 \%-84 \%$ and a specificity of $74 \%-$ $100 \%(23,28-30)$. 

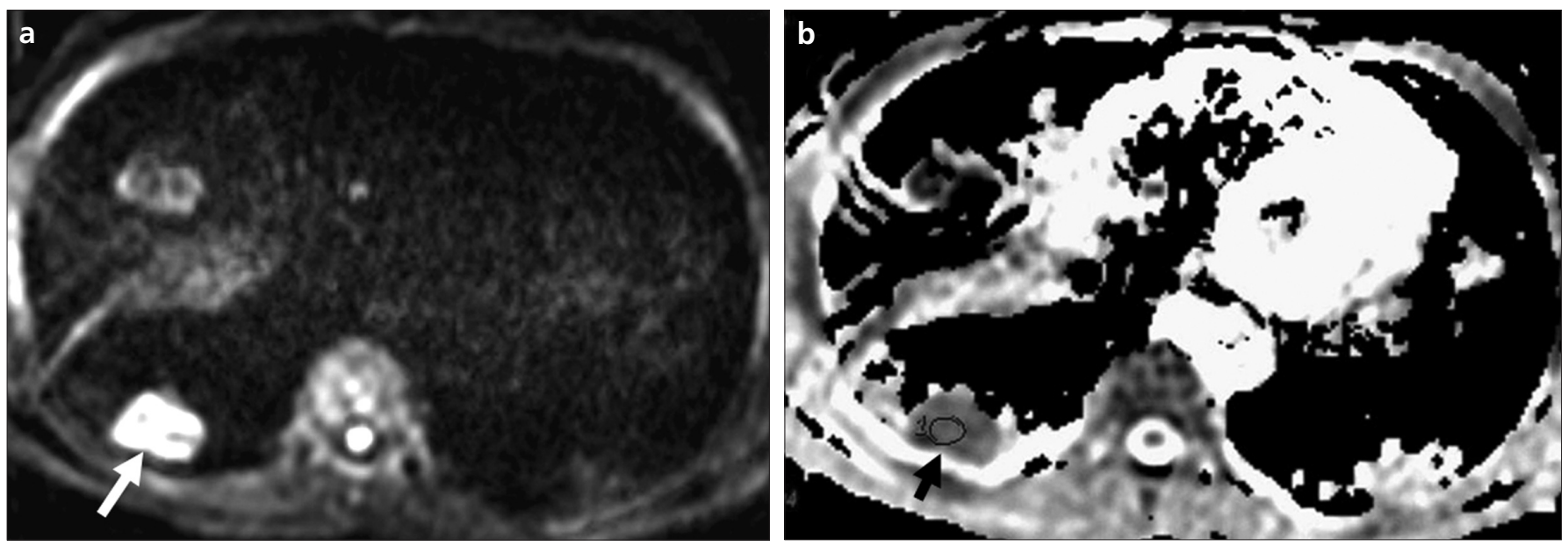

Figure 2. a, b. Transverse DWI (a) and corresponding ADC map (b) of a 52-year-old patient with squamous cell carcinoma. The peripheral mass in the laterobasal segment of the right lower lobe appears hyperintense relative to the spinal cord on the DWI image (a, white arrow) and shows restricted diffusion (ADC value, $1.10 \times 10^{-3} \mathrm{~mm}^{2} / \mathrm{s}$ ) on the ADC map (b, black arrow). Note the inflammatory lesion in the left lower lung with unrestricted diffusion.

Quantitative DWI has also been used for the tissue characterization of lung cancers. Matoba et al. (27) reported that the mean ADC value of adenocarcinoma was significantly higher than that of squamous cell carcinoma or large cell carcinoma $\left(2.1 \times 10^{-3} \mathrm{~mm}^{2} / \mathrm{s}\right.$ vs. $1.6 \times 10^{-3} \mathrm{~mm}^{2} / \mathrm{s}$ vs. $1.3 \times 10^{-3} \mathrm{~mm}^{2} / \mathrm{s}$, respectively). It was also reported that the mean ADC value of well-differentiated adenocarcinoma was significantly higher than the values for moderately and poorly differentiated squamous cell carcinoma and poorly differentiated adenocarcinoma. This finding is supported by Mori et al. (30), who reported that $39.6 \%(21 / 53)$ of welldifferentiated adenocarcinoma was negative on DWI, compared with $4.7 \%$ $(1 / 21)$ of squamous cell carcinoma. On the contrary, Koyama et al. (37) reported that quantitative DWI is less sensitive than STIR in the detection and subtype classification of pulmonary adenocarcinomas, particularly bronchioalveolar carcinoma. Therefore, DWI should always be evaluated in conjunction with conventional MRI sequences.

Another application of DWI is tumor detection in collapsed lungs, which is difficult with conventional modalities. The precise differentiation of the tumor from post-obstructive consolidation is important for clinical staging and radiotherapy planning. Qi et al. (32) compared the performance of T2W MRI, DWI, and contrast-enhanced CT in 33 cases of suspected lung cancer and post-obstructive consolidation. The authors were able to differentiate cancer from consolidation on CT, T2W MRI, and DWI in 14, 21 , and 26 patients, respectively. The combination of T2W MRI and DWI differentiated $88 \%(29 / 33)$ of cases, with higher interobserver agreement for DWI. Similarly, Baysal et al. (33) reported that the mean ADC of the central mass was significantly lower than that of post-obstructive consolidation.

Quantitative DWI has also been used to assess mediastinal lymph nodes. In an evaluation of 734 lymph nodes in 88 patients with non-small-cell lung carcinoma, Nomori et al. (35) reported a sensitivity of $70 \%$ and a specificity of $97 \%$ using an ADC cutoff value of $1.6 \times 10^{-3} \mathrm{~mm}^{2} / \mathrm{s}$. Similarly, Kosucu et al. (26) reported that the ADC of metastatic lymph nodes was significantly lower than that of benign nodes. Nakayama et al. (38) calculated the ADC difference between a lung cancer and a lymph node in 70 patients with non-small-cell lung cancer and found that the mean ADC difference in the lymph node group with metastases was significantly lower than that in the group without metastases. Using an ADC difference of $0.24 \times 10^{-3} \mathrm{~mm}^{2} / \mathrm{s}$ as a positive test threshold, the authors reported that the sensitivity, specificity, and accuracy were $69 \%, 100 \%$, and $94 \%$, respectively.

DWI has compared favorably to positron emission tomography (PET). In a series of 140 nodules/masses, Mori et al. (30) reported that the sensitivity of DWI was comparable to that of
PET (70\% vs. $72 \%)$, and its specificity was significantly higher (97\% vs. $79 \%$ ) because of fewer false positives for active inflammatory lesions with DWI. Nomori et al. (35) did not find a significant difference in the sensitivity, but DWI had significantly fewer false negative results (5/698 vs. 18/698), which resulted in higher specificity. Ohba et al. (39) found that DWI was comparable to PET in distinguishing non-smallcell lung cancer from benign pulmonary nodules in 110 patients with 124 pulmonary nodules.

DWI has evolved into a diagnostically useful tool for the characterization of pulmonary nodules and mediastinal lymph nodes. Potential future applications of DWI in lung cancer include monitoring the treatment response after chemotherapy or radiation, discriminating post-therapeutic changes from residual tumors, and detecting recurrent cancer.

\section{Breast applications}

DWI has been investigated as a diagnostic tool in breast cancer (40). Sinha et al. (41) were the first to demonstrate that ADC values could differentiate between normal, benign masses and malignancies in the breast. The range of $b$ values reported in the literature for breast DWI is $0-1000$. Two studies have investigated multiple combinations of $b$ values to determine their effect on image quality and the calculated ADC value $(42,43)$. The first study found no significant difference in the diagnostic performance of ADC 

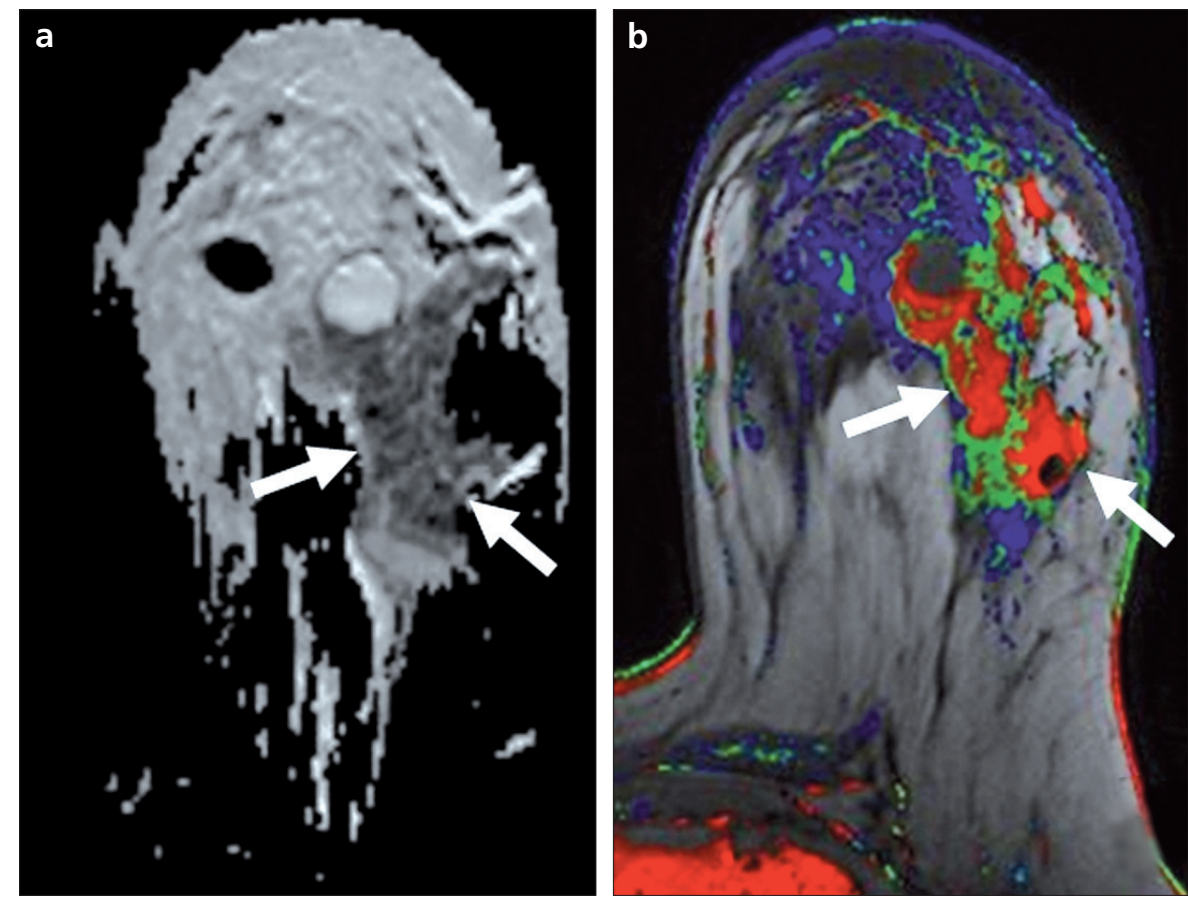

Figure 3. a, b. A 43-year-old patient newly diagnosed with breast cancer. ADC map (a) (DWI was acquired with $b$ values of 0 and $600 \mathrm{~s} / \mathrm{mm}^{2}$, TR/TE/FA 9548/64/90). Axial computeraided detection (CAD) color map (b) generated by the pharmacokinetic analysis of dynamic contrast-enhanced MRI. The ADC map demonstrates the lesion heterogeneity with the low-signal region on the ADC map (restricted diffusion) corresponding to the regions with a suspicious perfusion pattern (red and green areas on the CAD color map) (arrows). The histopathological analysis of the lesion revealed in-situ and infiltrating ductal carcinoma.

values obtained with different $b$ value combinations and suggested that ADC values based on $b$ values of 0 and 750 were preferred (43). Another study concluded that $b$ values of 50 and 850 resulted in the highest accuracy (95\%) (42). The optimum cut-off values varied in these studies, which was likely a result of different calculation methods and differences in patient populations (43-45). Despite the ability of DWI to statistically differentiate benign from malignant breast lesions, there is typically a considerable overlap of values in the two groups. Recently, a study by Costantini et al. (46) reported an inverse relationship between ADC values and tumor grade. Less aggressive tumors (Grade 1 and in situ lesions) displayed an average ADC value of $1.19 \times 10^{-3} \mathrm{~mm}^{2} / \mathrm{s}$, whereas more aggressive tumors (Grades 2 and 3 ) had an average ADC value of $0.96 \times 10^{-3}$ $\mathrm{mm}^{2} / \mathrm{s}$. Another study found a significant correlation between the average ADC value of invasive ductal carcinoma of the breast and estrogen receptor (ER) and HER2 expression (47).

Another attempt to improve the diagnostic performance of diffusion-weighted MRI in breast MRI was embodied in the suggestion of El Khouli et al. (48) to normalize the ADC value of breast lesions to the ADC value of the ipsilateral remote glandular tissue (Fig. 3). The normalization is thought to overcome factors that affect $A D C$ values, including ADC variations across the menstrual cycle (as reported previously by Partridge et al. [49]) and variations of scanning parameters. The normalized ADC value with a cut-off point of 0.7 significantly improved the diagnostic performance of DWI in discriminating benign from malignant lesions (48).

Reports have shown that ADC is useful in assessing the early (after the first cycle) (50) and late (after the third cycle) (51) tumor response to neoadjuvant chemotherapy when compared with morphological parameters such as tumor volume (50) and dynamic contrast-enhanced MRI parameters (52). Investigators have reported an inneoadjuvant chemotherapy. Sharma et al. (50) reported a $51 \% \pm 31.5 \%$ increase of the ADC value in responders and only a $14.3 \% \pm 13.1 \%$ increase in crease in the ADC value of lesions after nonresponders. The authors suggested a $15.7 \%$ cut-off value after two cycles with a sensitivity of $81 \%$, a specificity of $88 \%$, and an area under the curve (AUC) of 0.93 . A $23.8 \%$ increase in the ADC was also suggested as a cutoff value after three cycles of neoadjuvant chemotherapy with a sensitivity of $79 \%$, a specificity of $80 \%$, and an AUC of 0.87. Park et al. (51) reported a $47.9 \% \pm 4.8 \%$ increase in ADC in responders, whereas nonresponders demonstrated only an $18.1 \% \pm 4.5 \%$ increase. Pretreatment ADC values have also been investigated $(51,53)$. Nilsen et al. (53) did not find significant differences between the pretreatment ADC values of responders and nonresponders. On the other hand, Park et al. (51) reported that the pretreatment ADC values of responders were significantly lower than those of nonresponders and suggested a cut-off value of $1.17 \times 10^{-3} \mathrm{~mm}^{2} / \mathrm{s}$ for the response, with a sensitivity of $94 \%$, a specificity of $71 \%$, and an AUC of 0.89 .

\section{Abdominal applications}

The role of DWI in the abdomen has been relatively limited because of motion (respiration, peristaltic, and bulk) and susceptibility artifacts arising from gas in the bowel. With the development of faster imaging techniques, the ability to produce satisfactory abdominal DWI has improved.

The ADC values of abdominal tumors are variable because of differing amounts of cellularity, inflammation, and necrosis $(54,55)$ (Fig. 4).

DWI is able to differentiate between benign and malignant focal hepatic lesions, in many cases because of the higher ADC of benign lesions compared with malignant lesions (56-58). This finding is thought to be the result of cellular membranes impeding the mobility of water molecules. However, solid benign lesions, which are also highly cellular, also demonstrate decreased ADC values. When malignant liver lesions are cystic or necrotic, DWI is less useful (59).

To evaluate focal liver lesions with DWI, Holzapfel et al. (60) demonstrated that DWI using a respiratorytriggered SSEPI sequence ( $b$ values, 50 , $300,600 \mathrm{~s} / \mathrm{mm}^{2}$ ) permitted the characterization of small ( $\leq 10 \mathrm{~mm}$ diameter) focal liver lesions as benign or malignant with high accuracy and excellent interobserver agreement. In this study, 

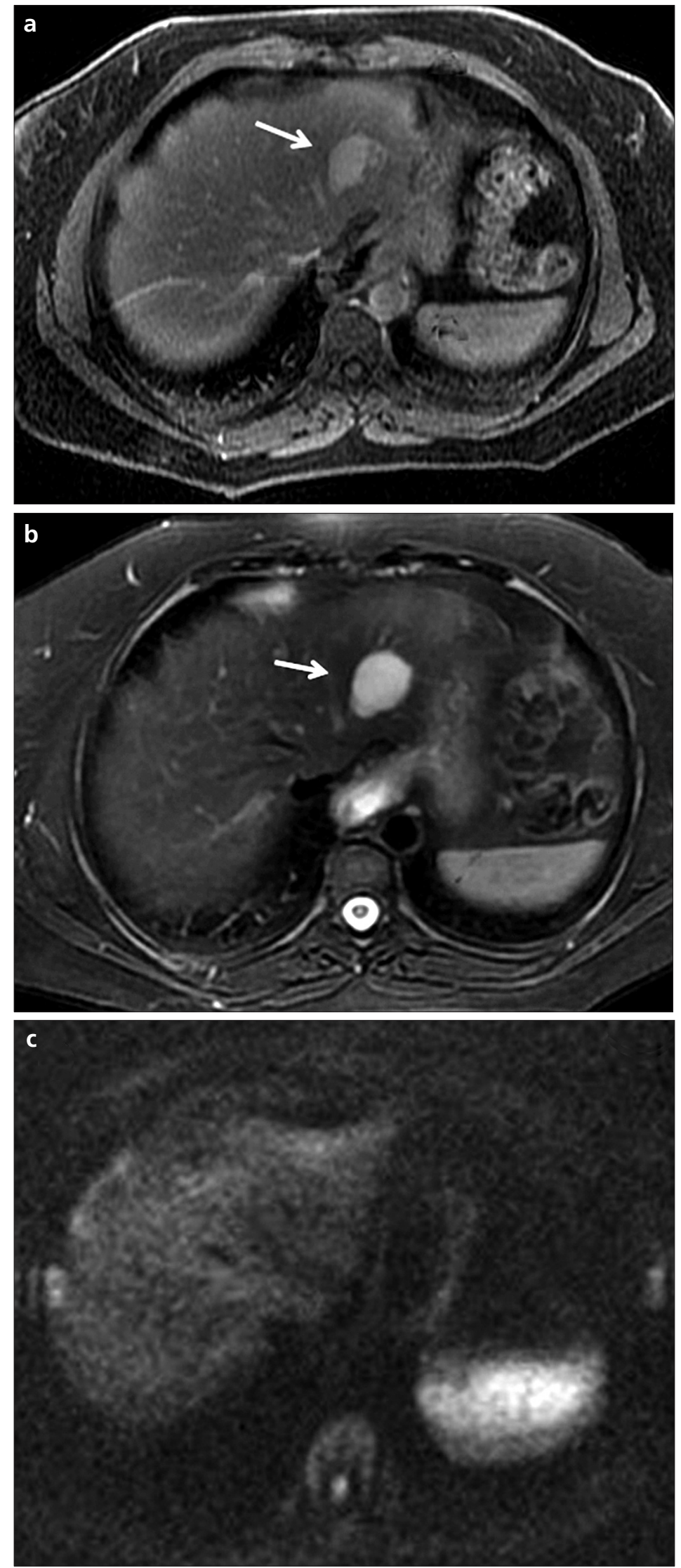

Figure 4. a-c. A 40-year-old man with a hepatic cyst. The lesion is hypointense on the T1-weighted image (arrow) (a), hyperintense on the T2-weighted image (arrow) (b), and isointense in DWI (c). The mean ADC value was $1.73 \mathrm{~mm}^{2} / \mathrm{s}$. application of a threshold ADC value of $1.41 \times 10^{-3} \mathrm{~mm}^{2} / \mathrm{s}$ allowed the differentiation of benign and malignant focal liver lesions with a sensitivity of $90.8 \%$ and a specificity of $89.9 \%$. The results of a recently published systematic meta-analysis by Xia et al. (61) indicated that DWI could be helpful in diagnosing malignant liver lesions. The use of DWI could increase the posttest probability from a baseline of $25 \%$ to $81 \%$, with a likelihood ratio of 13 , and would reduce the post-test probability to as low as 3\% when DWI was negative, with a likelihood ratio of 0.1 . This analysis implies that DWI could be helpful in increasing the accurate detection of malignant hepatic lesions (Fig. 5).

ADC values are less useful in patients with cirrhotic livers because cirrhosis and solid benign lesions also demonstrate low ADC values, leading to considerable overlap among disease categories. Necrosis and increased vascularity within hepatocellular carcinoma (HCC) may also alter diffusion, leading to falsely high ADC values (62). Nevertheless, there are reports that DWI showed a higher sensitivity than conventional MRI in detecting HCC in the cirrhotic liver $(98 \%$ for DWI vs. $83 \%-85 \%$ for MRI). For instance, Vandecaveye et al. (63) showed that DWI provided higher sensitivity and positive predictive values for the detection of HCC $<20 \mathrm{~mm}$ compared with conventional contrast-enhanced MRI (sensitivity and specificity, $91.2 \%$ and $82.9 \%$ vs. $67.6 \%$ and $61.6 \%$; positive predictive values, $81.6 \%$ and $59.0 \%$, respectively). However, DWI did not show significantly better results than conventional MRI in detecting HCC $>20 \mathrm{~mm}$. Thus, DWI provides a high negative predictive value for the presence of HCC and reduces the rate of unnecessary invasive diagnostic procedures and follow-up.

Hepatic metastases are the most common neoplasms of the liver. The usefulness of DWI in detecting liver metastases has been demonstrated in several studies. Taouli et al. (57) showed that metastatic liver tumors had the lowest ADC among malignant and benign focal lesions of the liver and found a significant difference in $\mathrm{ADC}$ values between benign and malignant lesions. Feuerlein et al. (64) pointed out that the performance of DWI was contingent on the pretest 

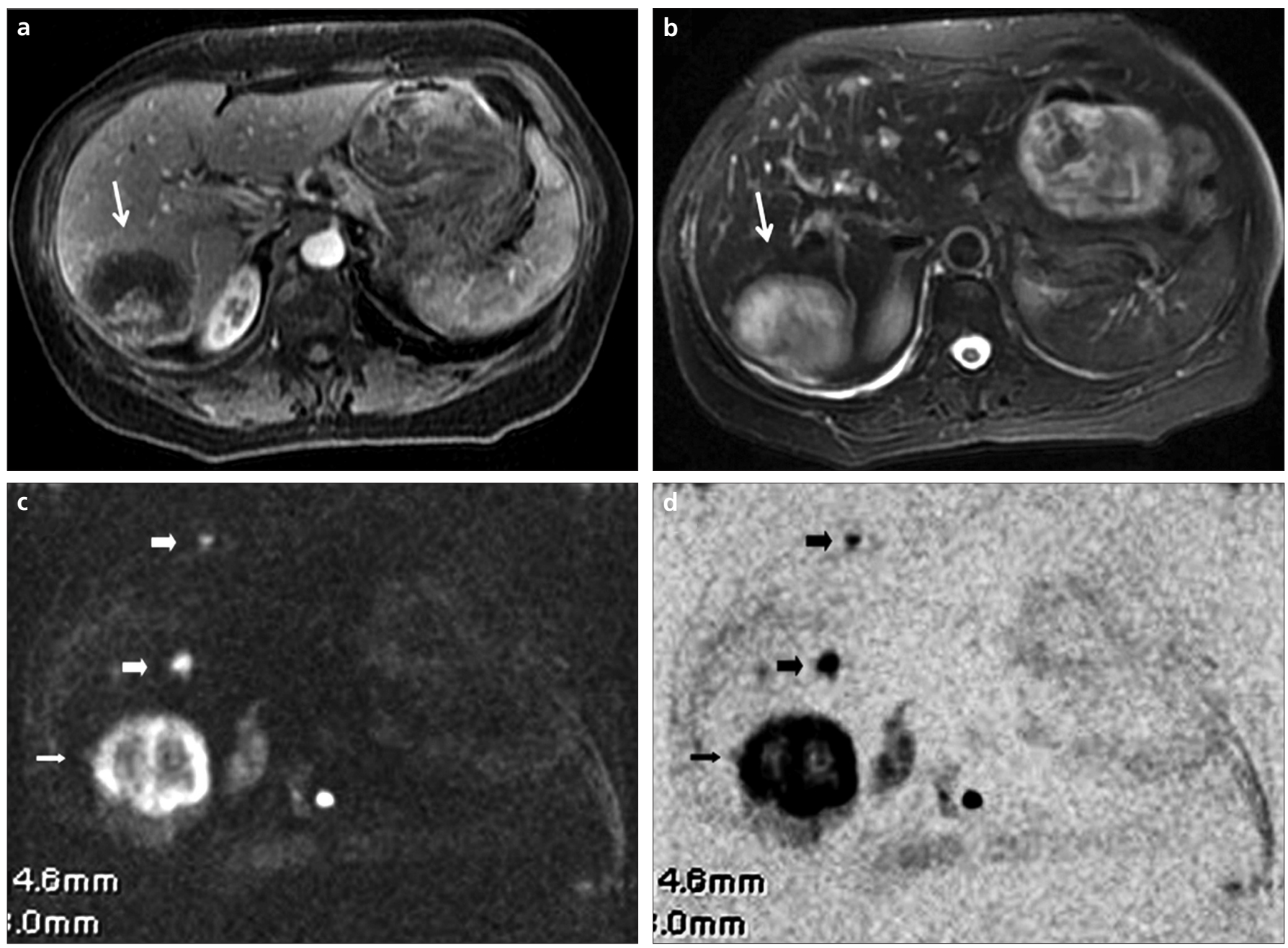

Figure 5. a-d. A 65-year-old male with pancreatic adenocarcinoma and liver metastases. The dominant liver lesion in segment 6 is hypointense on the T1-weighted image (a, arrow), hyperintense on the T2- weighted image (b, arrow), hyperintense on DWI (c, arrow), and appears black on the PET-like diffusion-weighted image (d, arrow). The mean ADC value was 0.63 mm²/s. Also note additional smaller metastases in segments 4 and 5 on DWI (c, d, thick arrows).

probability of malignancy (e.g., DWI performed better in patients with high pretest probabilities). Nasu et al. (65) assessed the diagnostic accuracy of respiratory-triggered DWI in combination with unenhanced MRI vs. superparamagnetic iron oxide (SPIO)-enhanced MRI (66). Based on a receiver operator characteristic analysis averaged over three observers, the sensitivity and specificity for SPIO-enhanced images were $66 \%$ and $90 \%$, compared with $82 \%$ and $94 \%$ for DWI.

Overall, the utility of DWI for monitoring the treatment response in HCC and metastases is very promising and may provide the possibility of individualized treatments. Early detection of the systemic chemotherapy response based on DWI findings has been investigated in several studies, and systemic chemotherapy of liver metastases had a good correlation between response and increased ADC values following treatment (67). Chan et al. (68) showed that DWI could be used to distinguish between hepatic abscesses and cystic or necrotic malignant liver tumors; the ADC values of abscess cavities were lower than those of cystic or necrotic malignant liver tumors.

Within the pancreas, there is a difference in the ADC values of the head, body, and tail. The pancreatic head and body have slightly higher ADC values than the tail (69). DWI findings of pancreatic adenocarcinoma suggest that ADC values are lower than in the normal pancreas, although there was considerable variability (70). The histopathological characteristics of tumors strongly influence the ADC values. When the tumor consists of prominent loose extracellular fibrosis (edematous fibrosis and loose collagen fibers) with a reduced cellular component, the ADC values are higher than in the normal pancreas. When there is a dense fibrosis and increased cellular elements, the ADC values are lower than in the normal pancreas (71). Pancreatic adenocarcinoma demonstrates restricted diffusion in DWI compared with the rest of the gland, with a high $b$ value $\left(1000 \mathrm{~s} / \mathrm{mm}^{2}\right)$. Utilizing ADC values, the mean sensitivity and specificity were reported to be $96.2 \%$ and $98.6 \%$, respectively (72). However, an overlap of ADC values between pancreatic adenocarcinoma and focal pancreatitis has been shown. Mass-forming focal pancreatitis has been shown to have either lower or higher ADC values than pancreatic adenocarcinoma, and these values may 

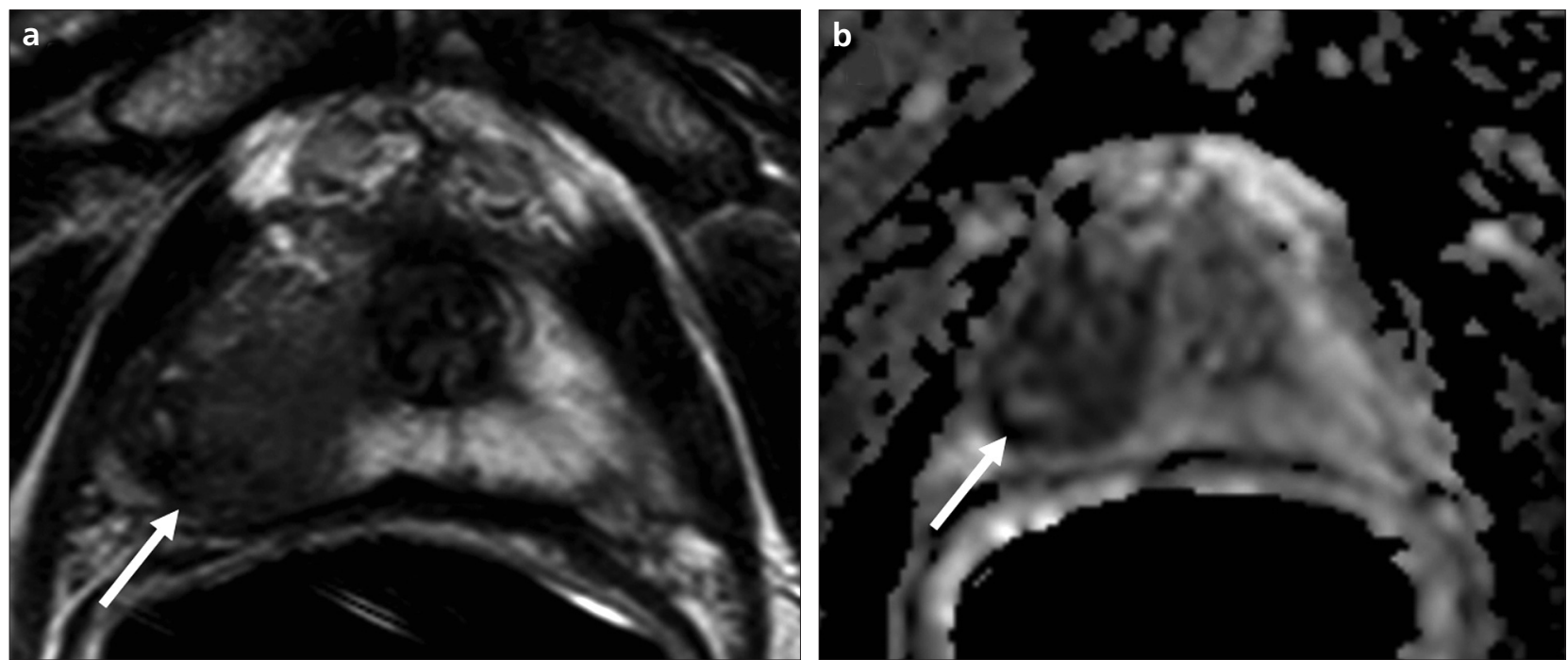

Figure 6. a, b. A 70-year-old man with prostate cancer. The axial T2W MR image (a) demonstrates a hypointense lesion in the right apical peripheral zone (arrow); an ADC map (b) derived from DWI localizes the tumor (arrow).

be indistinguishable from the ADC values in the remaining gland (70). Thus, DWI could be included as a complement to the standard MRI protocol for the pancreas. As noted previously, the ADC values of simple cysts and pseudocysts tend to be higher than the ADC values of pancreatic abscesses, hydatid cysts, and neoplastic cysts (73). Intraductal mucin-producing tumors demonstrate ADC values comparable to those of other pancreatic cystic lesions (74).

Among normal abdominal organs, the highest $\mathrm{ADC}$ is found in the kidney, followed by the liver, pancreas, and spleen (69). The ADC values of the upper pole of the kidney are higher than those of the central portion, most likely due to the radial orientation of structures within the kidney, such as renal vessels and tubules (75). The signal intensity of the most simple cysts drops significantly at a $b$ value of $500 \mathrm{~s} / \mathrm{mm}^{2}$ and dissipates completely at $b$ values of $1000-1500 \mathrm{~s} / \mathrm{mm}^{2}$. It has been shown that T1-hyperintense renal cysts and cystic masses (related to blood products or proteinaceous contents) have lower $\mathrm{ADC}$ values than their T1-hypointense counterparts (76). Manenti et al. (77) have reported significant differences among the ADC values of renal carcinomas and normal parenchyma; however, their analysis did not reveal a significant difference in the mean ADC value of the individual histological variants of renal carcinoma. In another study, Paudyal et al. (78) demonstrated that ADC values were significantly higher in renal cell carcinomas (RCC) than in transitional cell carcinomas. Further analysis of the histological subtypes of RCC demonstrated that clear-cell carcinomas had lower ADC values than non-clear-cell carcinomas, most likely because of differences in cellularity.

MRI also has been used to characterize adrenal masses as adrenal adenomas or malignancies. However, there are limited studies on the characterization of benign and malignant adrenal lesions using DWI. The signal intensity characteristics of up to $30 \%$ of benign adrenal adenomas may overlap with those of malignant lesions with conventional MRI (77), and it is not clear whether DWI can help differentiate between these two groups. According to recent studies, benign adrenal lesions could not be distinguished from malignant lesions with DWI because of a considerable overlap in ADC values (79). Importantly, DWI did not help distinguish lipidpoor from lipid-rich adenomas or distinguish between lipid-poor adenomas and other non-fatty lesions of the adrenal gland.

It has been shown that DWI has a greater sensitivity and specificity than MR cholangiopancreatography (MRCP) in the detection of extrahepatic cholangiocarcinoma (80). Cui et al. (80) concluded that the detection rate of extrahepatic cholangiocarcinoma was significantly higher for DWI (94.3\%) than for MRCP (74.3\%), and the positive and negative predictive values of DWI $(100 \%, 91.3 \%)$ were higher than those of MRCP $(81.3 \%$, $62.5 \%)$. Additionally, DWI was found to be a useful technique for screening peritoneal dissemination in a cohort of 107 patients with primary gastrointestinal or genitourinary tract malignancies (81).

\section{Male pelvis applications}

DWI applications in the male pelvis mainly focus on the imaging work-up of prostate cancer, especially in the era of serum prostate-specific screening. Normal prostate tissue is rich in glandular tissue, which has higher water diffusion rates. These differences can be depicted on ADC maps obtained with multiple $b$ field gradient values. Because DWI is an intrinsically low signal-to-noise sequence with noisy images and susceptibility artifacts, it benefits from higher field strengths and surface coils. However, higher field strengths can also introduce more challenges regarding susceptibility effects. The use of higher $b$ values (0 to 1000 and 2000 $\mathrm{s} / \mathrm{mm}^{2}$ ) can improve lesion detection at the expense of a lower signal-to-noise ratio (82-85). Prostate cancer lesions demonstrate hyperintense signal characteristics compared with the healthy peripheral zone on raw DWI, whereas they show a decreased signal intensity relative to healthy peripheral zone on ADC maps (86). DWI has demonstrated a wide range of sensitivities and specificities (57\%-93.3\% and 57\%-100\%, respectively) for tumor detection in various studies, depending on the field strength, imaging parameters, patient 
selection, and validation method used (84, 87-92). In addition to their tumor detection capability, ADC values have recently been shown to be useful in differentiating aggressive prostate cancers from indolent ones (93-96). DWI has a low signal noise ratio (SNR), but the emergence of high-field-strength magnets, the widespread use of endorectal coils and parallel imaging approaches will yield better SNR and, therefore, better spatial/temporal resolution for DWI. Additionally, the use of higher gradient strengths (e.g., $b$ values of 1000 to $2000 \mathrm{~s} / \mathrm{mm}^{2}$ ) improves the performance of DWI for lesion detection $(83-85,97)$. Moreover, DWI currently stands as the most promising quantitative MRI technique for improving our understanding of the nature of prostate cancer lesions (Fig. 6).

DWI has recently been reported to be useful in the detection and T-staging of bladder cancer. Matsuki et al. (98) reported that the ADC values of bladder cancers were lower than those of the surrounding normal tissues, including the bladder wall, in a cohort of 15 patients. El-Assmy et al. (99) confirmed these results. Abou-El-Ghar et al. (100) reported a high sensitivity and positive predictive value of $98.5 \%$ and $100 \%$, respectively, in 106 consecutive patients presenting with hematuria. Watanabe et al. (101) concluded that DWI has a higher specificity for Stage $\mathrm{T} 2$ or higher tumors, whereas Takeuchi et al. (102) reported improvements in both diagnosis and staging by adding DWI to conventional T2W MRI and gadolinium-enhanced MRI. The current literature on DWI use in bladder cancer is limited, but DWI remains a potentially useful adjunct (103).

\section{Female pelvis applications}

In the female pelvis, high- $b$-value (750-1000 s/mm²) DWI images and ADC maps should be interpreted with anatomic images to make a correct evaluation and avoid pitfalls (2, 104, 105).

The uterus and ovaries undergo morphological changes during the menstrual cycle, pregnancy and aging. The normal uterine corpus has three distinct zones on T2W images: the highintensity endometrial zone, the low-intensity junction zone and the intermediate-intensity myometrium. Similar zonal anatomy can be observed on an ADC map. Because the ADC value is affected by cell type, cellular packing, intracellular elements, membranes, macromolecules and microcirculation, menstrual cycle-specific physiological changes in the structures of different uterine zones may affect the width and signal intensity of each layer. The mean ADC value of the myometrium and endometrium tends to be lower at the end of the menstrual cycle than in other phases. Of course, it can be difficult to determine the timing of an MR scan relative to menstrual cycle phases in clinical practice. An accurate evaluation of low-intensity myometrial lesions, such as adenomyosis and leiomyoma, requires MRI to be performed during the late proliferative and secretory phases. The difference in the ADC values between malignant and nonmalignant lesions is comparable to the variation in the ADC values of normal structures during the menstrual cycle. Thus, the phase of the menstrual cycle must be considered when characterizing or monitoring lesions with ADC $(104,106,107)$.

DWI imaging of endometrial tumors has decreased ADC values (108-116). Endometrial carcinoma is clearly depicted as an area of increased signal intensity relative to the surrounding hypointense myometrium on DWI (116). ADC measurements have the potential to quantitatively differentiate Stage IA endometrial carcinoma from normal endometrium, endometrial dysplasia and benign diseases of the endometrium, such as endometrial hyperplasia, adenomyosis, submucosal leiomyoma, and endometrial polyps (108-116). DWI and combined DWI/T2W MRI can increase the overall detection sensitivity for endometrial carcinoma (113). Although lower ADC values in high-grade tumors have been reported, some studies have reported no correlation between ADC values and histological grades (115, 116). DWI is accurate for differentiating stage IB from stage IC and can be used as an adjunct for routine T2W MRI during pre-operative evaluation of endometrial cancer $(111,117)$.

The mean ADC value of cervical cancer lesions is lower than that of normal cervical tissue (112, 118-126). Hoogendam et al. (120) evaluated five different $b$ value combinations and found that the ADC-based differentiation of benign from malignant cervical tissue is independent of the tested $b$ value combination. Because the ADC values calculated by DWI data sets are acquired with a minimum of two different $b$ values, the $b$ value combination can also affect the ADC value. Therefore, imaging parameters and $b$ values should be considered when evaluating optimal ADC cut-off values to differentiate benign from malignant lesions (120). The ADC value of cervical squamous carcinoma was statistically lower than that of adenocarcinoma, and the ADC value of uterine cervical cancer correlated positively with differentiation and negatively with cellular density and tumor grade $(121,122)$. Pretreatment ADC values of uterine cervical cancer were significantly lower in patients who had a complete response with combined chemoradiation compared with patients who had a partial response (ADC values $0.80 \pm 0.07 \times 10^{-3}$ $\left.\mathrm{mm}^{2} / \mathrm{s}, \quad 0.93 \pm 0.09 \times 10^{-3} \mathrm{~mm}^{2} / \mathrm{s}\right) \quad(127)$. McVeigh et al. (124) found similar results, as pretreatment ADC values were lower in responders than nonresponders with squamous cell carcinoma $(P<$ 0.05). Harry et al. (128) did not find a correlation between pretreatment ADC values and tumor response. However, both ADC values and the change in ADC values after two weeks of therapy showed a significant correlation with eventual MRI and clinical response. It was concluded that DWI has the potential to provide a surrogate biomarker of treatment response in advanced cervical cancers. ADC values also significantly increased after treatment (123, 125-127). A prospective study of 61 patients with cervical cancer showed that all lymph nodes with a short-axis diameter larger than $5 \mathrm{~mm}$ were detected by DWI, regardless of whether they were benign or metastatic. The mean ADC values of enlarged metastatic lymph nodes (short-axis diameter larger than $5 \mathrm{~mm}$ ) were significantly lower than those of hyperplastic nodes $\left(1.05 \pm 0.20 \times 10^{-3} \mathrm{~mm}^{2} / \mathrm{s}, 1.29 \pm 0.19 \times 10^{-3}\right.$ $\left.\mathrm{mm}^{2} / \mathrm{s}, P<0.001\right)$ (129). Park et al. (130) investigated the feasibility of using ADC values and relative ADC (using the renal cortex as the reference site) to differentiate metastatic from nonmetastatic lymph nodes in cervical carcinoma and found similar results. Because ADC values vary according to numerous factors, such as MR acquisition parameters and magnetic field, the use of relative $\mathrm{ADC}$ can improve the diagnostic accuracy of DWI for detecting metastatic lymph nodes (130-132). Lin 
et al. (132) found that the combination of size and relative ADC values resulted in better sensitivity (25\% vs. $83 \%$ ) and similar specificity (98\% vs. 99\%) compared with conventional MRI. Primary tumor type (adenocarcinoma vs. adenosquamous carcinoma), focal infiltration with micrometastasis and associated necrosis also affect ADC values, and overlap between hyperplastic and metastatic lymph nodes could occur $(119,129-134)$.

The presence of an enhancing solid component in ovarian tumors may suggest malignancy; however, it is often difficult to differentiate malignancies from benign solid or cystic tumors with routine MRI. Takeuchi et al. (135) investigated the feasibility of using DWI to differentiate between benign and malignant ovarian tumors. The solid portion of the malignant tumors showed homogenous or heterogenous high intensity on DWI with low ADC values comparable to those of benign tumors. However, 30\% of thecomas also showed high intensity on DWI with low ADC values. Fujii et al. (136) investigated the DWI characteristics and ADC values of 123 ovarian tumors (42 malignant, 81 benign) and reported that the majority of malignant ovarian tumors and mature cystic teratomas, and almost half of the endometriomas, showed abnormal signal intensity on DWI, whereas most fibromas and other benign lesions did not. The main locations of abnormal signal intensity were solid portions in malignant ovarian tumors, cystic components suggestive of keratinoid substances and Rokitansky protuberances in mature cystic teratomas and intracystic clots in endometriomas. No significant difference was found in the mean and lowest ADC values of malignant and benign lesions, and it was concluded that DWI of ovarian lesions and the ADC values of the solid components are not useful for differentiating benign from malignant ovarian lesions. The reported ADC values in malignant ovarian tumors ranged between $0.88 \times 10^{-3} \mathrm{~mm}^{2} / \mathrm{s}$ and $2.28 \times 10^{-3} \mathrm{~mm}^{2} / \mathrm{s}(135-141)$. This variability in ADC values is probably due to tumor type, imaging parameters, $b$ value combination, and region of interest placement (whether or not the solid part was included). Low intensity on DWI with high ADC may suggest benign lesions; however, it may be occasionally difficult to differentiate benign from malignant lesions only on the basis of DWI (135). DWI provides a high contrast-to-noise ratio and enhanced detectability of even small malignant deposits. The combined interpretation of DWI and conventional MRI has been shown to increase accuracy in the staging of ovarian cancer by detecting more sites of peritoneal involvement (142).

Because of its noninvasive nature and ability to provide valuable qualitative and quantitative information, DWI has evolved into a diagnostically useful oncologic body imaging tool for lesion detection and characterization as well as treatment monitoring. The current evidence is sufficiently robust to support the incorporation of DWI into routine MRI. However, the standardization of data acquisition and analysis methods is necessary to achieve more reproducible results in both the detection and follow-up of neoplasms.

\section{Conflict of interest disclosure}

The authors declared no conflicts of interest.

\section{References}

1. Vilanova JC, Barcelo J. Diffusion-weighted whole-body MR screening. Eur J Radiol 2008; 67:440-447.

2. Koh DM, Collins DJ. Diffusion-weighted MRI in the body: applications and challenges in oncology. AJR Am J Roentgenol 2007; 188:1622-1635.

3. Kwee TC, Takahara T, Ochiai R, Nievelstein RA, Luijten PR. Diffusionweighted whole-body imaging with background body signal suppression (DWIBS): features and potential applications in oncology. Eur Radiol 2008; 18:1937-1952.

4. Koh DM, Takahara T, Imai Y, Collins DJ. Practical aspects of assessing tumors using clinical diffusion-weighted imaging in the body. Magn Reson Med Sci 2007; 6:211-224.

5. Thoeny HC, De Keyzer F. Extracranial applications of diffusion-weighted magnetic resonance imaging. Eur Radiol 2007; 17:1385-1393.

6. Provenzale JM, Mukundan S, Barboriak DP. Diffusion-weighted and perfusion MR imaging for brain tumor characterization and assessment of treatment response. Radiology 2006; 239:632-649.

7. Stejskal EO, Tanner JE. Spin diffusion measurements: spin-echo in the presence of a time dependent field gradient. J Chem Phys 1965; 42:288-292.

8. Dietrich O, Biffar A, Baur-Melnyk A, Reiser MF. Technical aspects of MR diffusion imaging of the body. Eur J Radiol 2010; 76:314-322.

9. Braren R, Altomonte J, Settles M, et al. Validation of preclinical multiparametric imaging for prediction of necrosis in hepatocellular carcinoma after embolization. J Hepatol 2011; Feb 24 [Epub ahead of print].
10. Oner AY, Celik H, Oktar SO, Tali T. Single breath-hold diffusion-weighted MRI of the liver with parallel imaging: initial experience. Clin Radiol 2006; 61:959965.

11. Taouli B, Martin AJ, Qayyum A, et al. Parallel imaging and diffusion tensor imaging for diffusion-weighted MRI of the liver: preliminary experience in healthy volunteers. AJR Am J Roentgenol 2004; 183:677-680.

12. Takahara T, Imai Y, Yamashita T, Yasuda S, Nasu S, Van Cauteren M. Diffusion weighted whole body imaging with background body signal suppression (DWIBS): technical improvement using free breathing, STIR and high resolution 3D display. Radiat Med 2004; 22:275282.

13. Le Bihan D, Breton E, Lallemand D, Aubin ML, Vignaud J, Laval-Jeantet M. Separation of diffusion and perfusion in intravoxel incoherent motion MR imaging. Radiology 1988; 168:497-505.

14. Luciani A, Vignaud A, Cavet M, et al. Liver cirrhosis: intravoxel incoherent motion MR imaging--pilot study. Radiology 2008; 249:891-899.

15. Riches SF, Payne GS, Morgan VA, et al. MRI in the detection of prostate cancer: combined apparent diffusion coefficient, metabolite ratio, and vascular parameters. AJR Am J Roentgenol 2009; 193:15831591.

16. Lemke A, Laun FB, Simon D, Stieltjes B, Schad LR. An in vivo verification of the intravoxel incoherent motion effect in diffusion-weighted imaging of the abdomen. Magn Reson Med 2010; 64:15801585.

17. Sigmund EE, Cho GY, Kim S, et al. Intravoxel incoherent motion imaging of tumor microenvironment in locally advanced breast cancer. Magn Reson Med 2011; 65:1437-1447.

18. Uhl M, Altehoefer C, Kontny U, Il'yasov $\mathrm{K}$, Buchert M, Langer M. MRI-diffusion imaging of neuroblastomas: first results and correlation to histology. Eur Radiol 2002; 12:2335-2338.

19. Humphries PD, Sebire NJ, Siegel MJ, Olsen OE. Tumors in pediatric patients at diffusion-weighted MR imaging: apparent diffusion coefficient and tumor cellularity. Radiology 2007; 245:848-854.

20. Alibek S, Cavallaro A, Aplas A, Uder M, Staatz G. Diffusion weighted imaging of pediatric and adolescent malignancies with regard to detection and delineation: initial experience. Acad Radiol 2009; $16: 866-871$.

21. Uhl M, Saueressig U, Koehler G, et al. Evaluation of tumour necrosis during chemotherapy with diffusion-weighted MR imaging: preliminary results in osteosarcomas. Pediatr Radiol 2006; 36:13061311.

22. Kwee TC, Takahara T, Vermoolen MA, Bierings MB, Mali WP, Nievelstein RA. Whole-body diffusion-weighted imaging for staging malignant lymphoma in children. Pediatr Radiol 2010; 40:15921602. 
23. Karabulut N, Martin DR, Yang $M$, Tallaksen RJ. MR imaging of the chest using a contrast-enhanced breath-hold modified three-dimensional gradientecho technique: comparison with twodimensional gradient-echo technique and multidetector CT. AJR Am J Roentgenol 2002; 179:1225-1233.

24. Kanauchi N, Oizumi H, Honma T, et al. Role of diffusion-weighted magnetic resonance imaging for predicting of tumor invasiveness for clinical stage IA nonsmall cell lung cancer. Eur J Cardiothorac Surg 2009; 35:706-710; discussion 710701

25. Luna A, Sanchez-Gonzalez J, Caro P. Diffusion-weighted imaging of the chest. Magn Reson Imaging Clin N Am 2011; 19:69-94.

26. Kosucu P, Tekinbas C, Erol M, et al. Mediastinal lymph nodes: assessment with diffusion-weighted MR imaging. J Magn Reson Imaging 2009; 30:292-297.

27. Matoba M, Tonami H, Kondou T, et al. Lung carcinoma: diffusion-weighted $\mathrm{mr}$ imaging--preliminary evaluation with apparent diffusion coefficient. Radiology 2007; 243:570-577.

28. Liu H, Liu Y, Yu T, Ye N. Usefulness of diffusion-weighted MR imaging in the evaluation of pulmonary lesions. Eur Radiol 2010; 20:807-815.

29. Uto T, Takehara $Y$, Nakamura $Y$, et al. Higher sensitivity and specificity for diffusion-weighted imaging of malignant lung lesions without apparent diffusion coefficient quantification. Radiology 2009; 252:247-254.

30. Mori $T$, Nomori $H$, Ikeda $K$, et al. Diffusion-weighted magnetic resonance imaging for diagnosing malignant pulmonary nodules/masses: comparison with positron emission tomography. J Thorac Oncol 2008; 3:358-364.

31. Karabulut N. Accuracy of diffusionweighted MR imaging for differentiation of pulmonary lesions. Radiology 2009; 253:899; author reply 899-900.

32. Qi LP, Zhang XP, Tang L, Li J, Sun YS, Zhu GY. Using diffusion-weighted MR imaging for tumor detection in the collapsed lung: a preliminary study. Eur Radiol 2009; 19:333-341.

33. Baysal T, Mutlu DY, Yologlu S. Diffusionweighted magnetic resonance imaging in differentiation of postobstructive consolidation from central lung carcinoma. Magn Reson Imaging 2009; 27:14471454.

34. Nakayama J, Miyasaka K, Omatsu T, et al. Metastases in mediastinal and hilar lymph nodes in patients with non-small cell lung cancer: quantitative assessment with diffusion-weighted magnetic resonance imaging and apparent diffusion coefficient. J Comput Assist Tomogr 2010; $34: 1-8$.

35. Nomori H, Mori T, Ikeda $\mathrm{K}$, et al. Diffusion-weighted magnetic resonance imaging can be used in place of positron emission tomography for $\mathrm{N}$ staging of non-small cell lung cancer with fewer false-positive results. J Thorac Cardiovasc Surg 2008; 135:816-822.
36. Satoh S, Kitazume Y, Ohdama S, Kimula Y, Taura S, Endo Y. Can malignant and benign pulmonary nodules be differentiated with diffusion-weighted MRI? AJR Am J Roentgenol 2008; 191:464-470.

37. Koyama H, Ohno Y, Aoyama N, et al. Comparison of STIR turbo SE imaging and diffusion-weighted imaging of the lung: capability for detection and subtype classification of pulmonary adenocarcinomas. Eur Radiol 2010; 20:790-800.

38. Nakayama J, Miyasaka K, Omatsu T, et al. Metastases in mediastinal and hilar lymph nodes in patients with non-small cell lung cancer: quantitative assessment with diffusion-weighted magnetic resonance imaging and apparent diffusion coefficient. J Comput Assist Tomogr 2010; $34: 1-8$.

39. Ohba $Y$, Nomori $H$, Mori $T$, et al. Is diffusion-weighted magnetic resonance imaging superior to positron emission tomography with fludeoxyglucose F 18 in imaging non-small cell lung cancer? J Thorac Cardiovasc Surg 2009; 138:439-445.

40. Englander SA, Ulug AM, Brem R, Glickson JD, van Zijl PC. Diffusion imaging of human breast. NMR Biomed 1997; 10:348352.

41. Sinha S, Lucas-Quesada FA, Sinha U, DeBruhl N, Bassett LW. In vivo diffusionweighted MRI of the breast: potential for lesion characterization. J Magn Reson Imaging 2002; 15:693-704.

42. Bogner W, Gruber S, Pinker $K$, et al. Diffusion-weighted MR for differentiation of breast lesions at 3.0 T: how does selection of diffusion protocols affect diagnosis? Radiology 2009; 253:341-351.

43. Pereira FP, Martins G, Figueiredo E, et al. Assessment of breast lesions with diffusion-weighted MRI: comparing the use of different $b$ values. AJR Am J Roentgenol 2009; 193:1030-1035.

44. Baron P, Dorrius MD, Kappert P, Oudkerk M, Sijens PE. Diffusion-weighted imaging of normal fibroglandular breast tissue: influence of microperfusion and fat suppression technique on the apparent diffusion coefficient. NMR Biomed 2010; 23:399-405.

45. Thoeny HC, De Keyzer F, Boesch C, Hermans R. Diffusion-weighted imaging of the parotid gland: Influence of the choice of b-values on the apparent diffusion coefficient value. J Magn Reson Imaging 2004; 20:786-790.

46. Costantini M, Belli $\mathrm{P}$, Rinaldi $\mathrm{P}$, et al Diffusion-weighted imaging in breast cancer: relationship between apparent diffusion coefficient and tumour aggressiveness. Clin Radiol 2010; 65:1005-1012.

47. Jeh SK, Kim SH, Kim HS, et al. Correlation of the apparent diffusion coefficient value and dynamic magnetic resonance imaging findings with prognostic factors in invasive ductal carcinoma. J Magn Reson Imaging 2011; 33:102-109.

48. El Khouli RH, Jacobs MA, Mezban SD, et al. Diffusion-weighted imaging improves the diagnostic accuracy of conventional 3.0-T breast MR imaging. Radiology 2010 256:64-73.
49. Partridge SC, McKinnon GC, Henry RG, Hylton NM. Menstrual cycle variation of apparent diffusion coefficients measured in the normal breast using MRI. J Magn Reson Imaging 2001; 14:433-438.

50. Sharma U, Danishad KK, Seenu V, Jagannathan NR. Longitudinal study of the assessment by MRI and diffusionweighted imaging of tumor response in patients with locally advanced breast cancer undergoing neoadjuvant chemotherapy. NMR Biomed 2009; 22:104113.

51. Park SH, Moon WK, Cho N, et al. Diffusion-weighted MR imaging: pretreatment prediction of response to neoadjuvant chemotherapy in patients with breast cancer. Radiology 2010; 257:5663.

52. Woodhams R, Kakita S, Hata $\mathrm{H}$, et al. Identification of residual breast carcinoma following neoadjuvant chemotherapy: diffusion-weighted imaging - comparison with contrast-enhanced MR imaging and pathologic findings. Radiology 2010; 254:357-366.

53. Nilsen L, Fangberget A, Geier O, Olsen DR, Seierstad T. Diffusion-weighted magnetic resonance imaging for pretreatment prediction and monitoring of treatment response of patients with locally advanced breast cancer undergoing neoadjuvant chemotherapy. Acta Oncol 2010; 49:354-360.

54. Schmidt GP, Kramer H, Reiser MF, Glaser C. Whole-body magnetic resonance imaging and positron emission tomography-computed tomography in oncology. Top Magn Reson Imaging 2007; 18:193202.

55. Charles-Edwards EM, deSouza NM. Diffusion-weighted magnetic resonance imaging and its application to cancer. Cancer Imaging 2006; 6:135-143.

56. Goshima S, Kanematsu M, Kondo H, et al. Diffusion-weighted imaging of the liver: optimizing $b$ value for the detection and characterization of benign and malignant hepatic lesions. J Magn Reson Imaging 2008; 28:691-697.

57. Taouli B, Vilgrain V, Dumont E, Daire JL, Fan B, Menu Y. Evaluation of liver diffusion isotropy and characterization of focal hepatic lesions with two single-shot echoplanar MR imaging sequences: prospective study in 66 patients. Radiology 2003; 226:71-78

58. Oruç E, Yıldırım N, Topal NB, Kılıçturgay S, Akgöz S, Savcı G. The role of diffusionweighted MRI in the classification of liver hydatid cysts and differentiation of simple cysts and abscesses from hydatid cysts. Diagn Interv Radiol 2010; 16:279-287.

59. Parikh T, Drew SJ, Lee VS, et al. Focal liver lesion detection and characterization with diffusion-weighted MR imaging: comparison with standard breath-hold T2-weighted imaging. Radiology 2008; 246:812-822.

60. Holzapfel K, Bruegel M, Eiber M, et al. Characterization of small $(</=10 \mathrm{~mm})$ focal liver lesions: value of respiratory-triggered echo-planar diffusion-weighted MR imaging. Eur J Radiol 2010; 76:89-95. 
61. Xia D, Jing J, Shen H, Wu J. Value of diffusion-weighted magnetic resonance images for discrimination of focal benign and malignant hepatic lesions: a metaanalysis. J Magn Reson Imaging 2010; 32:130-137.

62. Xu H, Li X, Xie JX, Yang ZH, Wang B. Diffusion-weighted magnetic resonance imaging of focal hepatic nodules in an experimental hepatocellular carcinoma rat model. Acad Radiol 2007; 14:279-286.

63. Vandecaveye V, De Keyzer F, Verslype C, et al. Diffusion-weighted MRI provides additional value to conventional dynamic contrast-enhanced MRI for detection of hepatocellular carcinoma. Eur Radiol 2009; 19:2456-2466.

64. Feuerlein S, Pauls S, Juchems MS, et al. Pitfalls in abdominal diffusion-weighted imaging: how predictive is restricted water diffusion for malignancy. AJR Am J Roentgenol 2009; 193:1070-1076.

65. Nasu K, Kuroki Y, Nawano S, et al. Hepatic metastases: diffusion-weighted sensitivity-encoding versus SPIO-enhanced MR imaging. Radiology 2006; 239:122-130.

66. Spiotta AM, Bhalla T, Hussain MS, et al. An analysis of inflation times during balloon-assisted aneurysm coil embolization and ischemic complications. Stroke 2011; 42:1051-1055.

67. Theilmann RJ, Borders R, Trouard TP, et al. Changes in water mobility measured by diffusion MRI predict response of metastatic breast cancer to chemotherapy. Neoplasia 2004; 6:831-837.

68. Chan JH, Tsui EY, Luk SH, et al. Diffusionweighted MR imaging of the liver: distinguishing hepatic abscess from cystic or necrotic tumor. Abdom Imaging 2001; 26:161-165.

69. Yoshikawa T, Kawamitsu H, Mitchell DG, et al. ADC measurement of abdominal organs and lesions using parallel imaging technique. AJR Am J Roentgenol 2006; 187:1521-1530.

70. Fattahi R, Balci NC, Perman WH, et al. Pancreatic diffusion-weighted imaging (DWI): comparison between mass-forming focal pancreatitis (FP), pancreatic cancer (PC), and normal pancreas. J Magn Reson Imaging 2009; 29:350-356.

71. Muraoka N, Uematsu H, Kimura H, et al. Apparent diffusion coefficient in pancreatic cancer: characterization and histopathological correlations. J Magn Reson Imaging 2008; 27:1302-1308.

72. Erturk SM, Ichikawa T, Motosugi U, Sou H, Araki T. Diffusion-weighted MR imaging in the evaluation of pancreatic exocrine function before and after secretin stimulation. Am J Gastroenterol 2006; 101:133-136.

73. Inan N, Arslan A, Akansel G, Anik Y, Demirci A. Diffusion-weighted imaging in the differential diagnosis of cystic lesions of the pancreas. AJR Am J Roentgenol 2008; 191: 1115-1121.

74. Irie $\mathrm{H}, \mathrm{Honda} \mathrm{H}$, Kuroiwa $\mathrm{T}$, et al. Measurement of the apparent diffusion coefficient in intraductal mucin-producing tumor of the pancreas by diffusion-weighted echo-planar MR imaging. Abdom Imaging 2002; 27:82-87.
75. Fukuda Y, Ohashi I, Hanafusa K, et al. Anisotropic diffusion in kidney: apparent diffusion coefficient measurements for clinical use. J Magn Reson Imaging 2000; $11: 156-160$.

76. Zhang J, Tehrani YM, Wang L, Ishill NM, Schwartz LH, Hricak H. Renal masses: characterization with diffusion-weighted MR imaging--a preliminary experience. Radiology 2008; 247:458-464.

77. Manenti G, Di Roma M, Mancino S, et al. Malignant renal neoplasms: correlation between ADC values and cellularity in diffusion weighted magnetic resonance imaging at 3 T. Radiol Med 2008; 113:199213.

78. Paudyal B, Paudyal P, Tsushima Y, et al. The role of the ADC value in the characterisation of renal carcinoma by diffusionweighted MRI. Br J Radiol 2010; 83:336343.

79. Miller FH, Wang Y, McCarthy RJ, et al. Utility of diffusion-weighted MRI in characterization of adrenal lesions. AJR Am J Roentgenol 2010; 194:W179-185.

80. Cui XY, Chen HW. Role of diffusionweighted magnetic resonance imaging in the diagnosis of extrahepatic cholangiocarcinoma. World J Gastroenterol 2010 16:3196-3201.

81. Satoh Y, Ichikawa T, Motosugi U, et al. Diagnosis of peritoneal dissemination: comparison of 18F-FDG PET/CT, diffusion-weighted MRI, and contrastenhanced MDCT. AJR Am J Roentgenol 2011; 196:447-453.

82. Lim HK, Kim JK, Kim KA, Cho KS. Prostate cancer: apparent diffusion coefficient map with T2-weighted images for detection-a multireader study. Radiology 2009; 250:145-151.

83. Tamada $\mathrm{T}$, Sone $\mathrm{T}$, Toshimitsu $\mathrm{S}$, et al. Age-related and zonal anatomical changes of apparent diffusion coefficient values in normal human prostatic tissues. J Magn Reson Imaging 2008; 27:552-556.

84. Kim CK, Park BK, Lee HM, Kwon GY. Value of diffusion-weighted imaging for the prediction of prostate cancer location at 3T using a phased-array coil: preliminary results. Invest Radiol 2007; 42:842847.

85. Kitajima K, Kaji Y, Kuroda K, Sugimura K. High b-value diffusion-weighted imaging in normal and malignant peripheral zone tissue of the prostate: effect of signal-tonoise ratio. Magn Reson Med Sci 2008; 7:93-99.

86. Gibbs P, Pickles MD, Turnbull LW. Diffusion imaging of the prostate at 3.0 tesla. Invest Radiol 2006; 41:185-188.

87. Tamada T, Sone T, Jo Y, et al. Prostate cancer: relationships between postbiopsy hemorrhage and tumor detectability at MR diagnosis. Radiology 2008; 248:531539.

88. Yağci AB, Ozari N, Aybek Z, Düzcan E. The value of diffusion-weighted MRI for prostate cancer detection and localization. Diagn Interv Radiol 2011; 17:130-134.

89. Haider MA, van der Kwast TH, Tanguay J, et al. Combined T2-weighted and diffusion-weighted MRI for localization of prostate cancer. AJR Am J Roentgenol 2007; 189:323-328.
90. Kozlowski P, Chang SD, Jones EC, Berean KW, Chen H, Goldenberg SL. Combined diffusion-weighted and dynamic contrast-enhanced MRI for prostate cancer diagnosis--correlation with biopsy and histopathology. J Magn Reson Imaging 2006; 24:108-113.

91. Reinsberg SA, Payne GS, Riches SF, et al. Combined use of diffusion-weighted MRI and $1 \mathrm{H}$ MR spectroscopy to increase accuracy in prostate cancer detection. AJR Am J Roentgenol 2007; 188:91-98.

92. Mazaheri Y, Shukla-Dave A, Hricak H, et al. Prostate cancer: identification with combined diffusion-weighted MR imaging and 3D 1H MR spectroscopic imaging--correlation with pathologic findings. Radiology 2008; 246:480-488.

93. Tamada T, Sone T, Jo Y, et al. Apparent diffusion coefficient values in peripheral and transition zones of the prostate: comparison between normal and malignant prostatic tissues and correlation with histologic grade. J Magn Reson Imaging 2008; 28:720-726.

94. deSouza NM, Riches SF, Vanas NJ, et al. Diffusion-weighted magnetic resonance imaging: a potential non-invasive marker of tumour aggressiveness in localized prostate cancer. Clin Radiol 2008; 63:774782.

95. Mazaheri Y, Hricak H, Fine SW, et al. Prostate tumor volume measurement with combined T2-weighted imaging and diffusion-weighted MR: correlation with pathologic tumor volume. Radiology 2009; 252:449-457.

96. Van As N, Charles-Edwards E, Jackson A, et al. Correlation of diffusion-weighted MRI with whole mount radical prostatectomy specimens. Br J Radiol 2008; $81: 456-462$.

97. Somford DM, Futterer JJ, Hambrock T, Barentsz JO. Diffusion and perfusion MR imaging of the prostate. Magn Reson Imaging Clin N Am 2008; 16:685-695.

98. Matsuki M, Inada $\mathrm{Y}$, Tatsugami $\mathrm{F}$, Tanikake M, Narabayashi I, Katsuoka Y. Diffusion-weighted MR imaging for urinary bladder carcinoma: initial results. Eur Radiol 2007; 17:201-204.

99. El-Assmy A, Abou-El-Ghar ME, Refaie HF, El-Diasty T. Diffusion-weighted MR imaging in diagnosis of superficial and invasive urinary bladder carcinoma: a preliminary prospective study. ScientificWorld Journal 2008; 8:364-370.

100. Abou-El-Ghar ME, El-Assmy A, Refaie HF, El-Diasty T. Bladder cancer: diagnosis with diffusion-weighted MR imaging in patients with gross hematuria. Radiology 2009; 251:415-421.

101. Watanabe H, Kanematsu M, Kondo H, et al. Preoperative $\mathrm{T}$ staging of urinary bladder cancer: does diffusion-weighted MRI have supplementary value? AJR Am J Roentgenol 2009; 192:1361-1366.

102. Takeuchi M, Sasaki S, Ito M, et al. Urinary bladder cancer: diffusion-weighted MR imaging--accuracy for diagnosing $\mathrm{T}$ stage and estimating histologic grade. Radiology 2009; 251:112-121. 
103. Kilickesmez O, Cimilli T, Inci E, et al. Diffusion-weighted MRI of urinary bladder and prostate cancers. Diagn Interv Radiol 2009; 15:104-110.

104. Padhani AR, Liu G, Koh DM, et al. Diffusion-weighted magnetic resonance imaging as a cancer biomarker: consensus and recommendations. Neoplasia 2009; 11:102-125.

105. Whittaker CS, Coady A, Culver L, Rustin G, Padwick M, Padhani AR. Diffusionweighted MR imaging of female pelvic tumors: a pictorial review. Radiographics 2009; 29:759-774; discussion 774-758.

106. Takeuchi M, Matsuzaki K, Nishitani H. Manifestations of the female reproductive organs on MR images: changes induced by various physiologic states. Radiographics 2010; 30:1147.

107. Kido A, Kataoka M, Koyama T, Yamamoto A, Saga T, Togashi K. Changes in apparent diffusion coefficients in the normal uterus during different phases of the menstrual cycle. Br J Radiol 2010; 83:524-528.

108. Masroor I, Zeeshan M, Afzal S, Ahmad N, Shafqat G. Diffusion weighted MR imaging (DWI) and ADC values in endometrial carcinoma. J Coll Physicians Surg Pak 2010; 20:709-713.

109. Wang J, Yu T, Bai R, Sun H, Zhao X, Li $Y$. The value of the apparent diffusion coefficient in differentiating stage IA endometrial carcinoma from normal endometrium and benign diseases of the endometrium: initial study at 3-T magnetic resonance scanner. J Comput Assist Tomogr 2010; 34:332-337.

110. Wang LX, Zhou CW, Ouyang H. Value of high-field MR diffusion-weighted MR imaging in the diagnosis of endometrial carcinoma. Zhonghua Zhong Liu Za Zhi 2009; 31:849-853.

111. Takeuchi M, Matsuzaki K, Nishitani $H$. Diffusion-weighted magnetic resonance imaging of endometrial cancer: differentiation from benign endometrial lesions and preoperative assessment of myometrial invasion. Acta Radiol 2009; 50:947-953.

112. Kilickesmez O, Bayramoglu S, Inci E, Cimilli T, Kayhan A. Quantitative diffusion-weighted magnetic resonance imaging of normal and diseased uterine zones. Acta Radiol 2009; 50:340-347.

113. Inada Y, Matsuki M, Nakai G, et al. Body diffusion-weighted MR imaging of uterine endometrial cancer: is it helpful in the detection of cancer in nonenhanced MR imaging? Eur J Radiol 2009; 70:122127

114. Fujii S, Matsusue E, Kigawa J, et al. Diagnostic accuracy of the apparent diffusion coefficient in differentiating benign from malignant uterine endometrial cavity lesions: initial results. Eur Radiol 2008; 18:384-389.

115. Shen SH, Chiou YY, Wang JH, et al. Diffusion-weighted single-shot echo-planar imaging with parallel technique in assessment of endometrial cancer. AJR Am J Roentgenol 2008; 190:481-488.

116. Tamai K, Koyama $T$, Saga $T$, et al. Diffusion-weighted MR imaging of uterine endometrial cancer. J Magn Reson Imaging 2007; 26:682-687.
117. Rechichi G, Galimberti S, Signorelli M, Perego P, Valsecchi MG, Sironi S. Myometrial invasion in endometrial cancer: diagnostic performance of diffusionweighted MR imaging at 1.5-T. Eur Radiol 2010; 20:754-762.

118. Nicolet V, Carignan L, Bourdon F, Prosmanne O. MR imaging of cervical carcinoma: a practical staging approach. Radiographics 2000; 20:1539-1549.

119. Chen YB, Hu CM, Chen GL, Hu D, Liao J. Staging of uterine cervical carcinoma: whole-body diffusion-weighted magnetic resonance imaging. Abdom Imaging 2010; Aug 21 [Epub ahead of print].

120. Hoogendam JP, Klerkx WM, de Kort GA et al. The influence of the b-value combination on apparent diffusion coefficient based differentiation between malignant and benign tissue in cervical cancer. J Magn Reson Imaging 2010; 32:376-382.

121. Liu Y, Bai R, Sun H, Liu H, Wang D. Diffusion-weighted magnetic resonance imaging of uterine cervical cancer. J Comput Assist Tomogr 2009; 33:858-862.

122. Payne GS, Schmidt M, Morgan VA, et al. Evaluation of magnetic resonance diffusion and spectroscopy measurements as predictive biomarkers in stage 1 cervical cancer. Gynecol Oncol 2010; 116:246252.

123. Chen J, Zhang Y, Liang B, Yang Z. The utility of diffusion-weighted MR imaging in cervical cancer. Eur J Radiol 2010; 74:e101-106.

124. McVeigh PZ, Syed AM, Milosevic M, Fyles A, Haider MA. Diffusion-weighted MRI in cervical cancer. Eur Radiol 2008; 18:10581064.

125. Zhang Y, Liang BL, Gao L, Ye RX, Shen J, Zhong JL. Diffusion weighted imaging features of normal uterine cervix and cervical carcinoma. Ai Zheng 2007; 26:508512.

126. Naganawa S, Sato C, Kumada H, Ishigaki T, Miura S, Takizawa O. Apparent diffusion coefficient in cervical cancer of the uterus: comparison with the normal uterine cervix. Eur Radiol 2005; 15:71-78.

127. Liu Y, Bai R, Sun H, Liu H, Zhao X, Li Y. Diffusion-weighted imaging in predicting and monitoring the response of uterine cervical cancer to combined chemoradiation. Clin Radiol 2009; 64:1067-1074.

128. Harry VN, Semple SI, Gilbert FJ, Parkin DE. Diffusion-weighted magnetic resonance imaging in the early detection of response to chemoradiation in cervical cancer. Gynecol Oncol 2008; 111:213-220.

129. Chen YB, Liao J, Xie R, Chen GL, Chen G. Discrimination of metastatic from hyperplastic pelvic lymph nodes in patients with cervical cancer by diffusion-weighted magnetic resonance imaging. Abdom Imaging 2009; 36:102-109.

130. Park SO, Kim JK, Kim KA, et al. Relative apparent diffusion coefficient: determination of reference site and validation of benefit for detecting metastatic lymph nodes in uterine cervical cancer. J Magn Reson Imaging 2009; 29:383-390.
131. Kim JK, Kim KA, Park BW, Kim N, Cho KS. Feasibility of diffusion-weighted imaging in the differentiation of metastatic from nonmetastatic lymph nodes: early experience. J Magn Reson Imaging 2008; 28:714-719.

132. Lin G, Ho KC, Wang JJ, et al. Detection of lymph node metastasis in cervical and uterine cancers by diffusion-weighted magnetic resonance imaging at 3T. J Magn Reson Imaging 2008; 28:128-135.

133. Roy C, Bierry G, Matau A, Bazille G, Pasquali R. Value of diffusion-weighted imaging to detect small malignant pelvic lymph nodes at 3 T. Eur Radiol 2010; 20:1803-1811.

134. Nakai G, Matsuki M, Inada $Y$, et al. Detection and evaluation of pelvic lymph nodes in patients with gynecologic malignancies using body diffusion-weighted magnetic resonance imaging. J Comput Assist Tomogr 2008; 32:764-768.

135. Takeuchi M, Matsuzaki K, Nishitani H. Diffusion-weighted magnetic resonance imaging of ovarian tumors: differentiation of benign and malignant solid components of ovarian masses. J Comput Assist Tomogr 2010; 34:173-176.

136. Fujii S, Kakite S, Nishihara K, et al. Diagnostic accuracy of diffusion-weighted imaging in differentiating benign from malignant ovarian lesions. J Magn Reson Imaging 2008; 28:1149-1156.

137. Bakir B, Bakan S, Tunaci $M$, et al. Diffusion-weighted imaging of solid or predominantly solid gynaecological adnexial masses: is it useful in the differential diagnosis? Br J Radiol 2011; 84:600-611.

138. Busard MP, Mijatovic V, van Kuijk C, Pieters-van den Bos IC, Hompes PG, van Waesberghe JH. Magnetic resonance imaging in the evaluation of (deep infiltrating) endometriosis: the value of diffusionweighted imaging. J Magn Reson Imaging 2010; 32:1003-1009.

139. Sala E, Rockall A, Rangarajan D, KubikHuch RA. The role of dynamic contrastenhanced and diffusion weighted magnetic resonance imaging in the female pelvis. Eur J Radiol 2010; 76:367-385.

140. Nakayama T, Yoshimitsu K, Irie H, et al. Diffusion-weighted echo-planar MR imaging and ADC mapping in the differential diagnosis of ovarian cystic masses: usefulness of detecting keratinoid substances in mature cystic teratomas. J Magn Reson Imaging 2005; 22:271-278.

141. Katayama M, Masui T, Kobayashi S, et al. Diffusion-weighted echo planar imaging of ovarian tumors: is it useful to measure apparent diffusion coefficients? J Comput Assist Tomogr 2002; 26:250-256.

142. Kyriazi S, Collins DJ, Morgan VA, Giles SL, deSouza NM. Diffusion-weighted imaging of peritoneal disease for noninvasive staging of advanced ovarian cancer. Radiographics 2010; 30:1269-1285. 